\title{
Ni Underlayer Effect for the Structure Development and Visible Light Photocatalytic Efficiency of Carbon-Doped $\mathrm{TiO}_{2}$ Film
}

\author{
Emilija DEMIKYTE ${ }^{*}$, Sandra SAKALAUSKAITE ${ }^{2}$, Neringa KULIESIENE ${ }^{3}$, Simona \\ TUCKUTE $^{4}$, Marius URBONAVICIUS ${ }^{5}$, Sarunas VARNAGIRIS ${ }^{6}$, \\ Rimantas DAUGELAVICIUS ${ }^{7}$, Martynas LELIS ${ }^{8}$ \\ ${ }^{1-3,7}$ Vytautas Magnus University, 8 Vileikos st., Kaunas 44404, Lithuania \\ ${ }^{1-8}$ Lithuanian Energy Institute, 3 Breslaujos st., Kaunas 44403, Lithuania
}

\begin{abstract}
Photocatalytic treatment of contaminated aqueous solutions makes use of the specific interaction between photocatalysts and ultra-violet or visible light irradiation. This method belongs to the wider class of Advanced Oxidation Processes that generates reactive oxygen species (peroxides, superoxide, hydroxyl radical, singlet oxygen, etc.) and uses them for the non-selective oxidation of various organic and inorganic compounds. In THE current study magnetron sputtering technique was used to deposit carbon-doped $\mathrm{TiO}_{2}$ films which are known to have significant photocatalytic activity in the visible light spectra and can be used for the neutralisation of contaminated solutions. Structural properties of the asdeposited films were analysed by XRD, XPS and AFM techniques, whereas their visible light photocatalytic activity was estimated by analysing Rhodamine B solution bleaching kinetics. When carbon-doped $\mathrm{TiO}_{2}$ photocatalysts were formed on borosilicate glass XRD analysis showed that they consisted of mixed phase (rutile-anatase) $\mathrm{TiO}_{2}$ where both phases contributed by similar parts. However, when the same deposition procedure was used to deposit carbon-doped $\mathrm{TiO}_{2}$ films on glass covered by Ni layer, formation of metastable anatase phase was enhanced. Estimation of visible light photocatalytic activity of the films revealed that $\mathrm{Ni}$ underlayer had positive effect for the efficiency of Rhodamine $\mathrm{B}$ solution bleaching and it could be beneficial for the practical wastewater treatment systems. It was suggested that observed improvement was mainly achieved due to the structural changes of $\mathrm{TiO}_{2}$ crystal phase, but other mechanisms like prevention of impurity diffusion from the glass substrate to the carbon-doped $\mathrm{TiO}_{2}$ film, or positive $\mathrm{Ni}$ doping effect could not be excluded completely.
\end{abstract}

Keywords - Carbon-doped $\mathrm{TiO}_{2}$; crystal structure; magnetron sputtering; visible light photocatalysis; water cleaning

\begin{tabular}{|ll}
\hline Nomenclature & \\
AOPs & Advanced Oxidation Processes \\
ITO & Indium Tin Oxide \\
DC & Direct current \\
MFC & Mass Flow Controller \\
XRD & X-ray Diffraction \\
XPS & X-ray photoelectron spectrometry \\
AFM & Atomic Force Microscope \\
\hline
\end{tabular}

* Corresponding author.

E-mail address: emilija.demikyte@stud.vdu.lt

(C)2021 Emilija Demikyte, Sandra Sakalauskaite, Neringa Kuliesiene, Simona Tuckute, 


\begin{tabular}{|lll|}
\hline RhB & Rhodamine B & - \\
at. $\%$ & atomic percentage & $\%$ \\
$\mathrm{Ra}$ & Arithmetic average roughness & $\mathrm{nm}$ \\
\hline
\end{tabular}

\section{INTRODUCTION}

During the last century viewpoints and official policies on environment issues have undergone several remarkable changes [1]. During the first half of the $20^{\text {th }}$ century society, politics, and industry were mostly focused on solving economic and social problems which were intensified by the two World Wars. In that context environmental pollution issue was hardly recognised by the public, almost unaccepted by the policy makers and ignored by the industry. In 1950s and 1960s people experienced several deadly smog episodes in Donora Pennsylvania (1948), London (1952, 1956), New York (1953), Los Angeles (1954) [2], started to observe fearful outcomes of the nuclear tests [3], and began to realise the potential toxicity of the globally used pesticides [4]. By witnessing these occurrences general public became aware of the environmental pollution issues and foundations for larger changes were laid up. It took few more decades to step up from the recognition of the problem to the delivery of the early significant responses, but at the end of the $20^{\text {th }}$ century 'stopping and prevention of environment pollution' became words of the daily political agenda [5], [6].

Unfortunately, more recent environment and climate change studies revealed that recognition of the problem and reaction to it was too slow and in general too weak. Accordingly, scientific community reasons that it is not enough only to limit or prevent the pollution but it is equally important to develop new methods to neutralise pollutants which are already present in the environment [7]. This ultimate change in the paradigm of the environment sustainability has made environment and climate research much more multidisciplinary with the significant emphasis on rising of public awareness [8], development and applications of new highly efficient technologies [9] and functional materials. For instance, catalysts make up the class of functional materials that are used to enable or favour the formation of the desired products and/or to suppress the formation of undesirable by-products. Traditionally their usage was basically limited to the industrial processes with a single purpose to make production feasible and economical [10]. But the change of environment sustainability paradigm introduced catalyst into various end-user products (for example vehicles with diesel engines) where catalyst sole role is to make product usage environmentally friendlier. Moreover, some specific catalysts help to create technologies and products that are purposefully designed to reduce energy consumption or to provide pollution cleaning solutions [11].

Advanced Oxidation Processes (AOPs) generates reactive oxygen species (peroxides, superoxide, hydroxyl radical, singlet oxygen, etc.) and uses them for the non-selective oxidation of various organic and inorganic compounds. Photocatalytic purification of waste water [12], disinfection of liquids (or environmental surfaces) [13] and self-cleaning windows [14] are just a few examples of sustainable environment oriented AOPs [15] which thrusted the development of $\mathrm{TiO}_{2}$ based photocatalysts research [16]. Up to now $\mathrm{TiO}_{2}$ synthesis has been realised by the countless number of methods based on sol-gel [17], microemulsionmediated processes [18], electrodeposition [19], hydro/solvothermal processes [20], anodisation [21], sonochemical [22] and microwave-assisted techniques [23], chemical vapour deposition [24], physical vapour deposition [25], spray pyrolysis [19], etc. Most of the early studies synthesised $\mathrm{TiO}_{2}$ by wet chemical methods and produced it in powder form. In addition to some trivial necessities like large surface area, comprehensive analysis of $\mathrm{TiO}_{2}$ 
powder brought out the importance of its crystallinity and phase composition (namely anatase/rutile ratio) [26], [27]. Moreover, it became clear that in order to increase $\mathrm{TiO}_{2}$ photocatalytic efficiency and to functionalise it in visible light spectra native band gap of approximately $3.2 \mathrm{eV}$ has to be reduced by doping [28], dye sensitisation [29], creating composites with semiconductors [30] or by using other techniques [31].

Various forms of $\mathrm{TiO}_{2}$ nanopowder can have exceptionally large specific surface area reaching more than $1400 \mathrm{~m}^{2} / \mathrm{g}$ [32]. Naturally, their intrinsic photocatalytic activity is high but their practical applications are often limited by other factors. First, after $\mathrm{TiO}_{2}$ powder are used for the photocatalytic 'cleaning' of contaminated solutions it is difficult to collect them back. Second, similarly to some other nanomaterials, although macroscopic forms of $\mathrm{TiO}_{2}$ are proven to be inert and not toxic [33] their nanopowder forms potentially can be harmful for the environment and living organisms [34], [35]. Accordingly, moving towards practical applications $\mathrm{TiO}_{2}$ based photocatlysts are immobilised on solid substrates.

Self-cleaning windows represent one of the potential $\mathrm{TiO}_{2}$ application areas and conventional soda lime glass was amongst early substrates which were used to support active $\mathrm{TiO}_{2}$ coatings [36]. Unfortunately, soon it was realised that sodium and calcium diffuse from the soda lime glass to the $\mathrm{TiO}_{2}$ matrix and reduce its photocatalytic efficiency significantly [37]. On the other hand, much more expensive fused silica glass (amorphous silica without added impurities) substrate was stable and no interdiffusion between $\mathrm{SiO}_{2}-\mathrm{TiO}_{2}$ was observed [37]. Ensuing studies involved more substrate types including ceramics [38], [39], metals [40], [41], polymers [42], [43] and other. Some of them (for example ITO glass or crown glass coated with a $\mathrm{SiO}_{2}$ layer [44]) provided relatively similar result to the fused silica glass, whereas others (for example glazed ceramic tiles and $6061 \mathrm{Al}$ alloy [45]) decreased the photocatalytic efficiency of $\mathrm{TiO}_{2}$ coatings.

In current study we further analysed how support affects the photocatalytic activity of $\mathrm{TiO}_{2}$ based photocatalyst. More specifically we used magnetron sputtering process to deposit carbon doped $\mathrm{TiO}_{2}$ films on bare borosilicate glass and the same glass pre-covered by nickel layer. Changes in crystal structure, surface roughness and efficiency of photocatalytic Rhodamine B dye degradation under visible light irradiation are presented.

\section{Methods ANd Methodology}

\subsection{Carbon-Doped $\mathrm{TiO}_{2}$ Film Deposition}

Borosilicate discs made from D263 glass (SCHOTT) with diameter of $30 \mathrm{~mm}$ were selected as film substrates. In comparison to traditional soda lime glass, D263 glass contains significantly lower amounts of various additive elements, maintains higher stability at elevated temperatures and has high chemical resistance. Most importantly, it has already been successfully used with $\mathrm{TiO}_{2}$ based films in our previous studies [46], [47].

Film deposition process was implemented in the custom modified physical vapor deposition system equipped with rotary and cryogenic vacuum pumps (PVD-75, Kurt J. Lesker Company). Base vacuum level before each experiment was not worse when $1 \times 10^{-7}$ mbar. Prior to film deposition, borosilicate glass substrate was cleaned by supplying $600 \mathrm{~V}$ DC bias to the sample holder and initiating oxygen plasma $\left(1 \times 10^{-1} \mathrm{mbar}\right.$ pressure $)$ for $10 \mathrm{~min}$. 


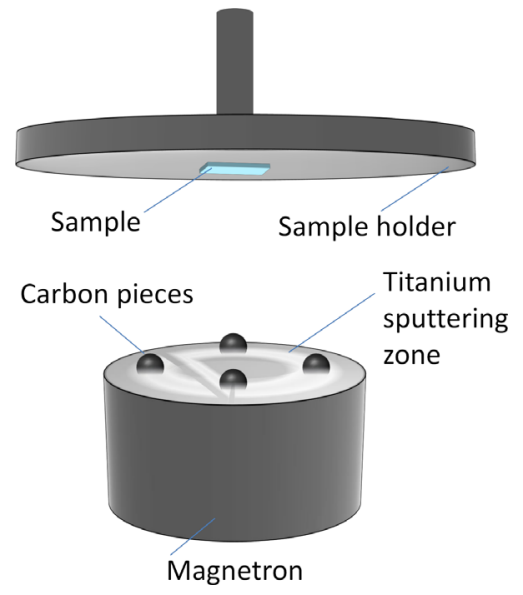

Fig. 1. Experimental set-up scheme during carbon-doped $\mathrm{TiO}_{2}$ formation.

Carbon-doped $\mathrm{TiO}_{2}$ films were deposited using unbalanced magnetron sputtering technique. $99.99 \%$ purity $\mathrm{Ti}$ disc $(76 \mathrm{~mm}$ diameter) was used as a cathode for Torrus 3 magnetron (Kurt J. Lesker Company). For the in-situ $\mathrm{TiO}_{2}$ film doping four graphite pieces were placed on Ti cathode as shown in Fig. 1. The size of carbon-covered area on Ti cathode was approximately one $\mathrm{cm}^{2}$ for each graphite piece. The selected amount of carbon was predetermined experimentally finding optimal conditions for the formation of carbon-doped $\mathrm{TiO}_{2}$ films. Each deposition process was started at room temperature and no auxiliary heat treatment was used during or after the deposition. During carbon-doped $\mathrm{TiO}_{2}$ film deposition total $\mathrm{Ar}-\mathrm{O}_{2}$ gas mixture (MFC flow ratio 5:1) pressure was kept constant at $6 \times 10^{-3}$ mbar. The distance between the sample holder and Ti cathode was fixed at $4 \mathrm{~cm}$. As samples were placed directly above the magnetron, sample size was significantly smaller than the cathode diameter and there were no indications of films inhomogeneity therefore deposition of $\mathrm{TiO}_{2}$ films was performed without any additional rotation of the substrate. During experiments magnetron sputtering was performed for $180 \mathrm{~min}$ with pulsed DC power supply operating at $300 \mathrm{~W}$ power. When Ni layer was used, it was pre-deposited at pure argon atmosphere $\left(6 \times 10^{-3}\right.$ mbar) using DC powered magnetron $(170 \mathrm{~W})$ with $99.99 \%$ purity $\mathrm{Ni}$ disc. The approximate thickness of the carbon-doped $\mathrm{TiO}_{2}$ and $\mathrm{Ni}$ layers was $1300 \mathrm{~nm}$ and $200 \mathrm{~nm}$ respectively. All used deposition parameters were preselected experimentally during pilot studies not reported here.

\subsection{Structural Characterization of the Films}

Phase structure of the deposited carbon-doped $\mathrm{TiO}_{2}$ films was identified by X-Ray diffractometer (XRD, Bruker D8) operating with $\mathrm{Cu} \mathrm{K \alpha}$ radiation. Crystallite sizes were evaluated by Topas software with Lorentzian convolution. Chemical state and elemental composition of the films was analysed by X-ray photoelectron spectrometer (XPS, PHI Versaprobe 5000) using monochromated $1486.6 \mathrm{eV}$ Al radiation, $25 \mathrm{~W}$ beam power, $100 \mu \mathrm{m}$ beam size and $45^{\circ}$ measurement angle. Sample charging was compensated using dual neutralization system consisting of low energy electron beam and ion beam. The thickness of as-deposited carbon-doped $\mathrm{TiO}_{2}$ films was measured using stylus profiler (Ambios XP-200). Surface morphology and roughness was evaluated by an atomic force microscope (AFM, Microtestmachines NT-206). Arithmetic average roughness parameter ( $\mathrm{Ra}$ ) values were 
calculated by measuring 3 to 5 different areas $(23 \times 23 \mu \mathrm{m}$ size $)$ of the samples and calculating their mean value.

\subsection{Photocatalytic Efficiency of the Films}

Photocatalytic bleaching of aqueous Methylene Blue, Rhodamine B (RhB) and other dye solutions is one of the most widely adopted ways to assess the potential of the photocatalyst to be used for the neutralisation (oxidation) of the harmful compounds and/or microorganisms (bacteria, viruses) [48]. Accordingly, in current study photocatalytic properties of carbondoped $\mathrm{TiO}_{2}$ films were assessed by the photocatalytic bleaching of RhB. Daylight (DL) LED lamp (Solis-3C, $5700 \mathrm{~K}$, Thorlabs) was used as the light irradiation source. The sample was positioned $230 \mathrm{~mm}$ below the DL lamp. Irradiation intensity at the surface of the sample was approximately $65 \mathrm{~mW} / \mathrm{cm}^{2}$ (measured with Thorlabs PM16-401 Power meter). The samples were placed into the quartz glass petri dish with the diameter of $45 \mathrm{~mm} .10 \mathrm{~mL}$ of $10 \mathrm{mg} / \mathrm{L}$ concentration aqueous $\mathrm{RhB}$ solution was syringed above the sample. In order to minimize evaporation of $\mathrm{RhB}$ solution, the top of the petri dish was covered by $500 \mu \mathrm{m}$ thick fused silica disc. The magnetic stirrer was used to ensure mixing of solution with $500 \mathrm{rpm}$. Prior to the illumination experiment the samples with mentioned conditions were kept in the dark for 1 hour to ensure the adsorption equilibrium. During the experiment, the petri dish with sample was mounted on the Peltier element, which maintained the solution temperature at $20^{\circ} \mathrm{C}$.

Photocatalytic degradation of RhB solution was evaluated by measuring its concentration changes (UV-VIS spectrophotometer, Jasco V-650). The strongest peak at $554.5 \mathrm{~nm}$ wavelength was used for actual value measurement. All the measurements were performed with 30 minutes interval using $1.5 \mathrm{~mL}$ of RhB solution. After the measurement, which took less than 2 minutes, the solution was syringed back to the petri dish for further degradation. Photolysis measurement (treatment of RhB solution with bare glass substrate irradiated by the same light source) was used as the control sample.

\section{RESULTS AND DISCUSSION}

\subsection{Structural Properties of the Carbon-Doped $\mathrm{TiO}_{2}$ Films}

XPS surface analysis (Fig. 2) of Carbon-doped $\mathrm{TiO}_{2}$ film has confirmed that at the surface there were only three expected elements: $\mathrm{Ti}, \mathrm{O}$ and $\mathrm{C}$ (part of the carbon is detected due to the adventitious contamination from atmosphere). Ti $2 \mathrm{p}$ spectra had Ti $2 \mathrm{p} 3 / 2$ peak located at $458.7 \mathrm{eV}$ and Ti $2 \mathrm{p}$ peak at $464.4 \mathrm{eV}$. Peak positions and their separation $(5.7 \mathrm{eV}$ ) correspond to the binding energies of corresponding values for Ti(IV) oxide [49]. Other oxidative states of Ti were not observed by XPS. O 1s peaks at approximately 530.0 and $531.6 \mathrm{eV}$ were assigned to the $\mathrm{Ti}-\mathrm{O}$ bonds in the $\mathrm{TiO}_{2}$ lattice and to the hydroxyl groups or water moisture adsorbed from the atmosphere. Unfortunately, sputtering by Ar ions disturbs titanium spectra severely and it loses chemical information. Accordingly, it was not possible to confirm that in the bulk titanium remains in the same chemical state as on the surface, but elemental analysis of sputtered points confirmed that it still maintains small fraction of carbon impurities (approximately 2 at. \%), while $\mathrm{Ti}$ and $\mathrm{O}$ concentrations were approximately 31-32 and $65-67$ at. $\%$, respectively. 

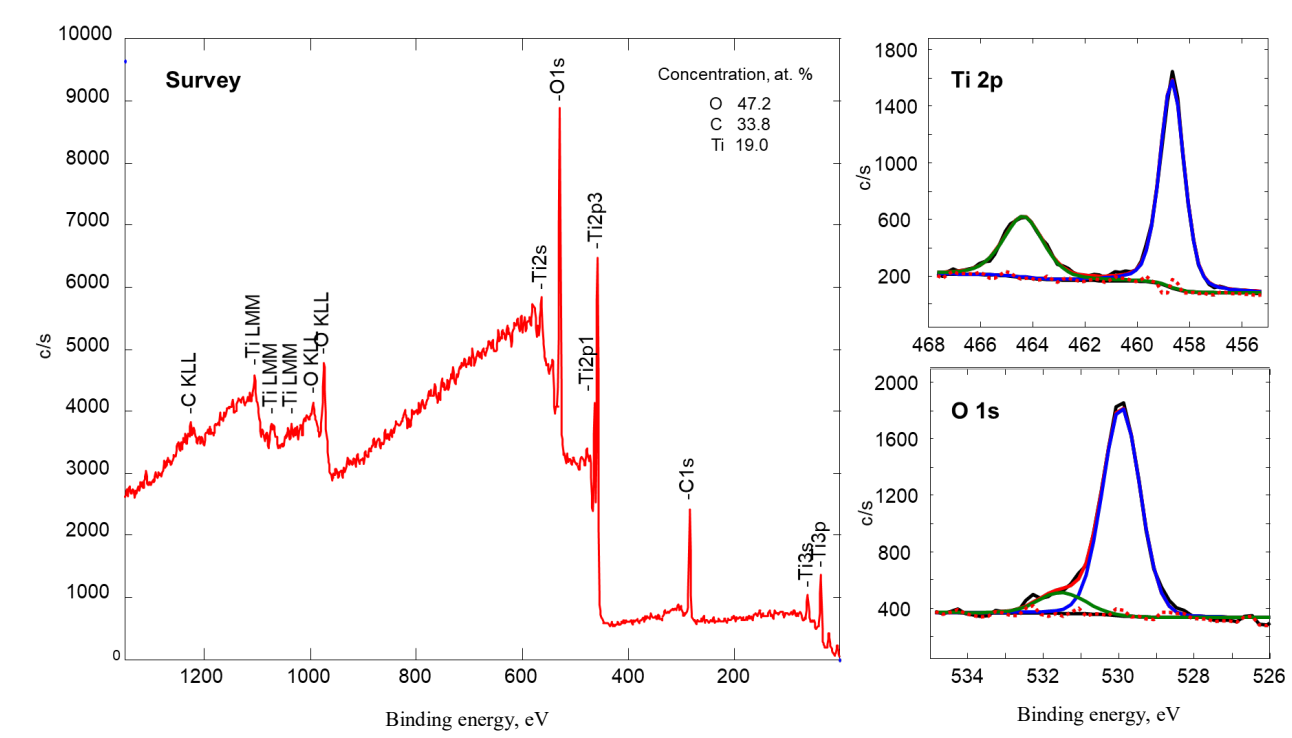

Fig. 2. Survey and high resolution elemental XPS spectra of the as deposited carbon-doped $\mathrm{TiO}_{2}$ films.

XRD crystal structure analysis of magnetron sputter deposited carbon-doped $\mathrm{TiO}_{2}$ films (Fig. 3) showed that films consisted of preferentially oriented anatase (metastable phase) and rutile (the most stable $\mathrm{TiO}_{2}$ form) phase mixture.

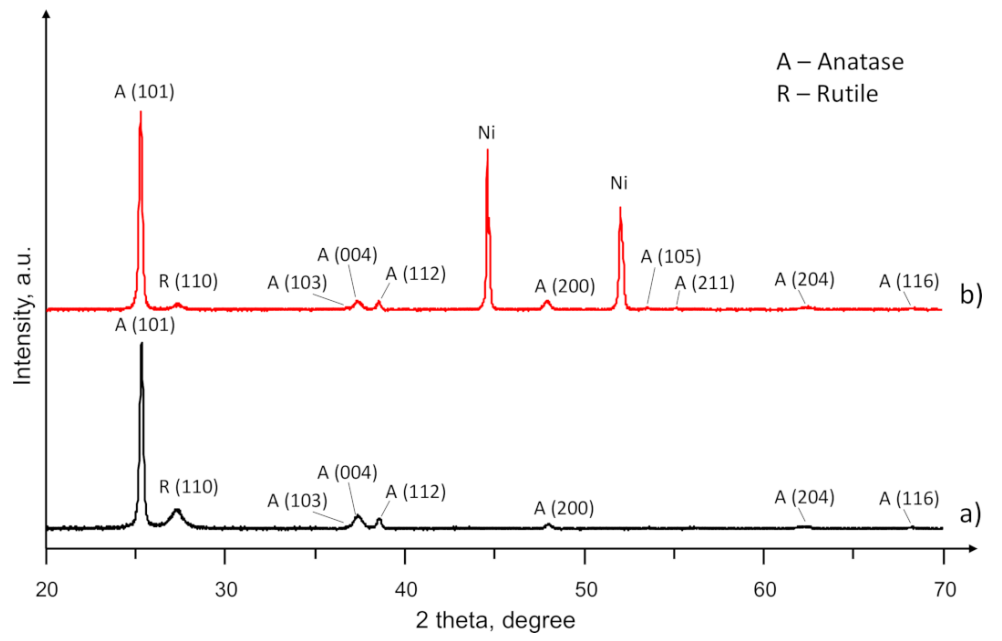

Fig. 3. XRD patterns of as deposited films: a) carbon-doped $\mathrm{TiO}_{2}$ film deposited directly on borosilicate glass substrate; b) carbon-doped $\mathrm{TiO}_{2}$ film deposited on $\mathrm{Ni}$ underlayer.

Rietveld refinement revealed that Ni underlayer effect for the crystallite size of anatase and rutile phases is not significant, but its effect on phase ratio is more pronounced (Table 1). Later fact has important practical meaning because different $\mathrm{TiO}_{2}$ phases differ by their photocatalytic response: rutile has the widest band gap and the lowest photocatalytic response; anatase photocatalytic efficiency is considerably higher; but the highest efficiency is reached for the anatase mixture with a small share of rutile (up to few tenths of percent) 
[27], [50], [51]. Previously it was observed that during magnetron sputtering process carbondoped $\mathrm{TiO}_{2}$ films initially has the tendency to form a phase mixture with a larger share of rutile phase which shifts towards anatase as film thickness increases [52]. It could be assumed that in the case of thicker films internal microstrains acts as the main factor which stabilizes anatase formation. Whereas in current study carbon-doped $\mathrm{TiO}_{2}$ thickness is equal for the two films and is low in comparison [52] study. Therefore, anatase stabilization factor is different and it probably can be ascribed to the Ni underlayer.

Table 1. Structural Parameters of As-Deposited Carbon-Doped TiO 2 Films

\begin{tabular}{lcccccc}
\hline Substrate & Thickness & $\begin{array}{l}\text { Anatase } \\
\text { crystallite size }\end{array}$ & $\begin{array}{l}\text { Rutile } \\
\text { crystallite size }\end{array}$ & $\begin{array}{l}\text { Anatase } \\
\text { fraction }\end{array}$ & $\begin{array}{l}\text { Rutile } \\
\text { fraction }\end{array}$ & $\begin{array}{l}\text { Arithmetic average } \\
\text { roughness, Ra }\end{array}$ \\
\hline $\begin{array}{l}\text { Borosilicate glass } \\
\begin{array}{l}\text { Borosilicate glass } \\
\text { coated by Ni }\end{array}\end{array}$ & $1300 \mathrm{~nm}$ & $61 \mathrm{~nm}$ & $10 \mathrm{~nm}$ & $56 \%$ & $44 \%$ & $2.1 \mathrm{~nm}$ \\
\hline
\end{tabular}

Despite relatively large $1300 \mathrm{~nm}$ film thickness and 55-60 $\mathrm{nm}$ anatase phase crystallite size surface roughness of the as-deposited films was low (Fig. 4). Arithmetic average roughness (Ra) values for carbon-doped films deposited directly on the glass and on Ni underlayer were only $2.1 \mathrm{~nm}$ and $6.1 \mathrm{~nm}$, respectively. Also, it can be noticed, that carbon-doped $\mathrm{TiO}_{2}$ film on $\mathrm{Ni}$ underlayer had significant long-range waviness, whereas films deposited directly on borosilicate glass retain flatter surface with repetition of approximately $500 \mathrm{~nm}$ diameter nanostructures. The observed morphological surface characteristics did not differ substantially, but subtle changes indicate possibility of slightly different film growth modes. Surface features of the film deposited directly on borosilicate glass can be considered as the result Frank-van der Merwe (layer-by-layer) film growth mode, whereas film deposition on $\mathrm{Ni}$ underlayer has some characteristics which are more typical for the Stranski-Krastanov (layer-plus-island) growth mode. Such differences in growth modes can be explained by the stronger affinity between titanium oxide and borosilicate glass which mainly consists of silicon dioxide and boron trioxide. At the same time, this subtle change in growth mode correlates with the stabilization of metastable anatase phase which was discussed above.
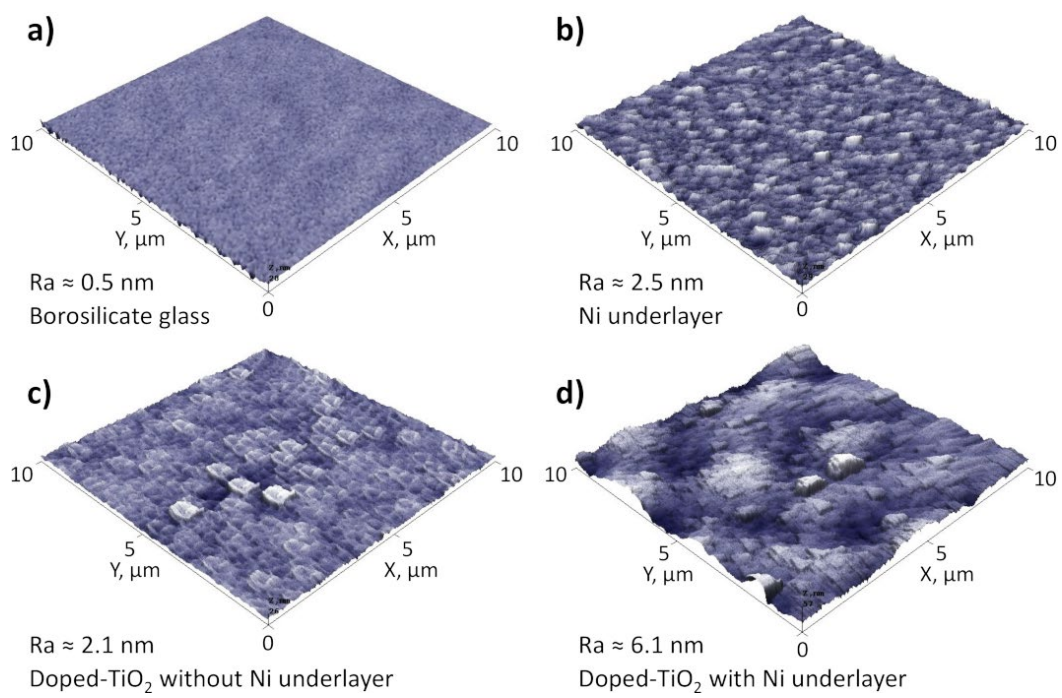

Fig. 4. 3D AFM surface images: a) uncovered borosilicate glass; b) Ni film on borosilicate glass; c) carbon-doped $\mathrm{TiO}_{2}$ film deposited directly on borosilicate glass substrate; d) carbon-doped $\mathrm{TiO}_{2}$ film deposited on Ni underlayer. 
Results of the photocatalytic RhB solution bleaching by the carbon-doped $\mathrm{TiO}_{2}$ films irradiated by the visible light are presented in Fig. 5. The rate constant of RhB photocatalytic degradation (first-order reaction constants, $\mathrm{k}$ values) under visible light without photocatalyst was approximately $4 \times 10^{-4} \mathrm{~min}^{-1}$. With photocatalyst corresponding rate constants increased several times and reached $22 \times 10^{-4} \mathrm{~min}^{-1}$ and $27 \times 10^{-4} \mathrm{~min}^{-1}$ for carbon-doped $\mathrm{TiO}_{2}$ film deposited directly on glass and Ni underlayer respectively. The positive effect by caused by $\mathrm{Ni}$ underlayer can have several explanations. First, it presumably alters the growth mode of the film and shifts anatase:rutile ratio to the anatase side. Higher efficiency of anatase phase $\mathrm{TiO}_{2}$ has been proven by photocatalytic bacteria treatment in urban waste water [53] as well as by theoretical and experimental studies using non-organic compounds [50], [51]. Second, although borosilicate glass is chemically more stable than traditional soda lime glass, it still contains a fraction of harmful elements [37] which potentially can diffuse from the glass to the film. In this respect $\mathrm{Ni}$ layer serves as a blocking element in preventing semiconductive photocatalyst from poisoning. Third, it is known that decorating $\mathrm{TiO}_{2}$ catalyst by some of the noble metals has positive effect for the photocatalytic disinfection of bacteria [54]. Similarly, $\mathrm{TiO}_{2}$ films coated on stainless steel [55] and foam nickel [56] substrates, also showed stronger antibacterial effect and photocatalytic activity than using glass substrate. Finally, in this particular study nickel impurities were not observed directly (by XPS) neither at the surface nor in the subsurface layers of the carbon-doped $\mathrm{TiO}_{2}$ film. But due to the relatively large thickness of the film our XPS sputtering was not performed throughout all of the coating, therefore it cannot be excluded that some Ni impurities are not diffusing to the carbon-doped $\mathrm{TiO}_{2}$ structure. Positive effect of titanium doping by Ni was reported at [56], but how nickel would affect the electronic structure of carbon-doped $\mathrm{TiO}_{2}$ remains unknown. If in fact $\mathrm{Ni}$ would diffuse, this factor potentially could add new electronic levels between the valence and conduction bands of $\mathrm{TiO}_{2}$ and enhance its activation by visible light adsorption caused by electrons moving between these intermediate levels.

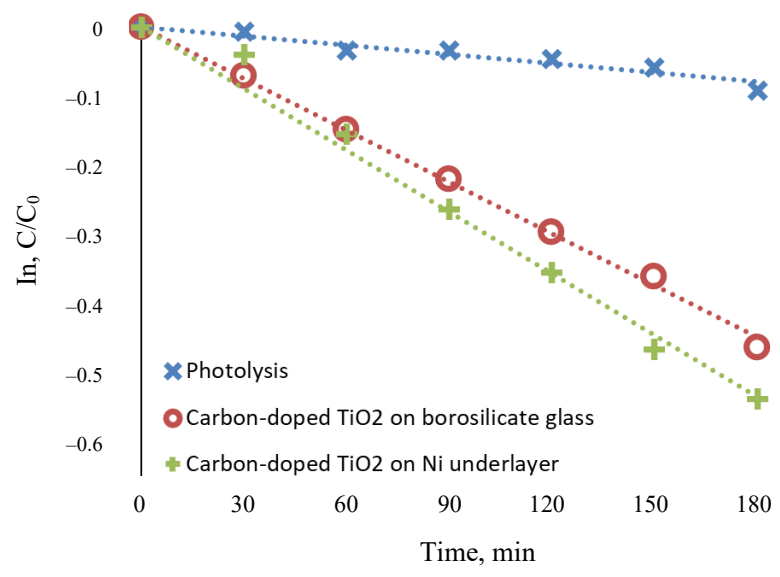

Fig. 5. RhB solution bleaching by the visible light activated carbon-doped $\mathrm{TiO}_{2}$ films.

\section{Conclusions}

Carbon-doped $\mathrm{TiO}_{2}$ films were successfully deposited by magnetron sputtering technique. When films were formed on borosilicate glass XRD analysis showed that they consisted of 
mixed phase (rutile-anatase) $\mathrm{TiO}_{2}$ where both phases contributed by similar parts. However, when the same deposition procedure was used to deposit carbon-doped $\mathrm{TiO}_{2}$ films on glass covered by $\mathrm{Ni}$ layer, formation of the metastable anatase phase was enhanced. Estimation of visible light photocatalytic activity of the films revealed that $\mathrm{Ni}$ underlayer had positive effect for the efficiency of RhB solution bleaching. Earlier reports have demonstrated that anatase phase $\mathrm{TiO}_{2}$ had stronger antibacterial effect and larger photocatalytic activity. Accordingly, it was suggested that observed improvement of $\mathrm{RhB}$ solution bleaching was mainly achieved due to the structural changes of $\mathrm{TiO}_{2}$ crystal phase, but other mechanisms like prevention of impurity diffusion from the glass substrate to the carbon-doped $\mathrm{TiO}_{2}$ film, or positive Ni doping effect could not be excluded completely. More detailed examination of the latter two possibilities will be one the objects of our wider study of substrate effects for the $\mathrm{TiO}_{2}$ and $\mathrm{ZnO}$ based photocatalysts.

\section{ACKNOWLEDGEMENT}

This research is funded by the European Social Fund according to the activity 'Improvement of researchers' qualification by implementing world-class R\&D projects' of Measure No. 09.3.3-LMT-K-712, project 'Investigation of the application of $\mathrm{TiO}_{2}$ and $\mathrm{ZnO}$ for the visible light assisted photocatalytical disinfection of the biologically contaminated water' (09.3.3-LMTK-712-01-0175). The authors express gratitude for Mindaugas Aikas, Rolandas Uscila and Deimante Vasiliauske for their valuable input in current work.

\section{REFERENCES}

[1] Lorraine E. Environmentalism. Encyclopedia Britannica 2020 [Online]. [Accessed 15.03.2021]. Available: https://www.britannica.com/topic/environmentalism

[2] Thomas C. Sustainability and the American Naturalist Tradition. Revisiting Henry David Thoreau, Aldo Leopold, Rachel Carson, and Edward O. Wilson. Bielefeld, 2018.

[3] Prăvălie R. Nuclear weapons tests and environmental consequences: a global perspective. Ambio 2014:43(6):729-744. https://doi.org/10.1007/s13280-014-0491-1

[4] Carson R. Silent Spring. Houghton Mifflin Company, 1962.

[5] United Nations. Report of the World Commission on Environment and Development: Our Common Future. UN, 1987.

[6] Annibaldi V., et al. Renewable Energy Policies: Bibliometric Review and Policy Implications. Environmental and Climate Technologies 2020:24:403-417. https://doi.org/10.2478/rtuect-2020-0112

[7] IPCC. 2021: Climate Change 2021: The Physical Science Basis. The Working Group I contribution to the Sixth Assessment Report. Geneva: IPCC, 2021.

[8] Priedniece V., et al. Treatment of Particulate Matter Pollution: People's Attitude and Readiness to Act. Environmental and Climate Technologies 2020:24:231-246. https://doi.org/10.2478/rtuect-2020-0069

[9] Muizniece I., Zihare L., Blumberga D. Obtaining the Factors Affecting Bioeconomy. Environmental and Climate Technologies 2019:23:277-291. https://doi.org/10.2478/rtuect-2019-0018

[10] Wacławek S., Padil V. V. T., Černík M. Major Advances and Challenges in Heterogeneous Catalysis for Environmental Applications: A Review. Ecological Chemistry and Engineering S 2018:25(1):9-34. https://doi.org/10.1515/eces2018-0001

[11] Han C., et al. Catalysis for Environmental Applications. Sustainable Catalysis. Weinheim: Wiley-vch Verlag GMBH \& co. kgaa, 2018:207-230. https://doi.org/10.1002/9783527693030.ch8

[12] Saravanan N., Sasikumar K. S. K. Waste water treatment process using Nano TiO2. Mater. Today Proc. 2020:33:25702572. https://doi.org/10.1016/j.matpr.2019.12.143

[13] García-Espinoza J. D., et al. Photo-assisted electrochemical advanced oxidation processes for the disinfection of aqueous solutions: A review. Chemosphere 2021:274:129957. https://doi.org/10.1016/j.chemosphere.2021.129957

[14] Banerjee S., Dionysiou D. D., Pillai S. C. Self-cleaning applications of TiO2 by photo-induced hydrophilicity and photocatalysis. Appl. Catal. B Environ. 2015:176-177:396-428. https://doi.org/10.1016/j.apcatb.2015.03.058

[15] Chen Y., et al. Advanced oxidation processes for water disinfection: Features, mechanisms and prospects. Chem. Eng. J. 2020:409:128207. https://doi.org/10.1016/j.cej.2020.128207

[16] Chen D., et al. Photocatalytic degradation of organic pollutants using $\mathrm{TiO}_{2}$-based photocatalysts: A review. J. Clean. Prod. 2020:268:121725. https://doi.org/10.1016/j.jclepro.2020.121725

[17] Cynthia S., Sagadevan S. Physicochemical and magnetic properties of pure and Fe doped $\mathrm{TiO}_{2}$ nanoparticles synthesized by sol-gel method. Mater. Today Proc. In Press, 2020. https://doi.org/10.1016/j.matpr.2020.08.225 
[18] Lu C. H., Wu W. H., Kale R. B. Microemulsion-mediated hydrothermal synthesis of photocatalytic TiO $\mathrm{T}_{2}$ powders. $J$. Hazard. Mater. 2008:154(1-3):649-654. https://doi.org/10.1016/j.jhazmat.2007.10.074

[19] Srikanth B., et al. Recent advancements in supporting materials for immobilised photocatalytic applications in waste water treatment. J. Environ. Manage. 2017:200:60-78. https://doi.org/10.1016/j.jenvman.2017.05.063

[20] Chen J., et al. Morphology and photocatalytic activity of $\mathrm{TiO}_{2} / \mathrm{MXene}$ composites by in-situ solvothermal method. Ceram. Int. 2020:46(12):20088-20096. https://doi.org/10.1016/j.ceramint.2020.05.083

[21] Li H., et al. Synthesis and investigation of $\mathrm{TiO}_{2}$ nanotube arrays prepared by anodization and their photocatalytic activity. Ceram. Int. 2012:38(7):5791-5797. https://doi.org/10.1016/j.ceramint.2012.04.026

[22] Wattanawikkam C., Pecharapa W. Structural studies and photocatalytic properties of Mn and $\mathrm{Zn}$ co-doping on TiO prepared by single step sonochemical method. Radiat. Phys. Chem. 2020:171:108714. https://doi.org/10.1016/j.radphyschem.2020.108714

[23] Paradisi E., et al. Effect of isopropanol co-product on the long-term stability of $\mathrm{TiO}_{2}$ nanoparticle suspensions produced by microwave-assisted synthesis. Chem. Eng. Process. - Process Intensif. 2021:159:108242. https://doi.org/10.1016/j.cep.2020.108242

[24] Lee H., et al. The synthesis and coating process of $\mathrm{TiO}_{2}$ nanoparticles using CVD process. Powder Technol. 2011:214(1):66-68. https://doi.org/10.1016/j.powtec.2011.07.036

[25] De Vietro N., Tursi A., Beneduci A. Photocatalytic inactivation of Escherichia coli bacteria in water using low pressure plasma deposited $\mathrm{TiO}_{2}$ cellulose fabric. Photochem. Photobiol. Sci. 2019:18(9):2248-2258. https://doi.org/10.1039/c9pp00050j

[26] Diebold U. The surface science of titanium dioxide. Surf. Sci. Rep. 2003:48(5-8):53-229. https://doi.org/10.1016/S0167-5729(02)00100-0

[27] X. Jiang et al., 'Anatase and rutile in evonik aeroxide P25: Heterojunctioned or individual nanoparticles?,' Catal. Today 2018:300:12-17. https://doi.org/10.1016/j.cattod.2017.06.010.

[28] Chen Y., et al. The fabrication of self-floating $\mathrm{Ti}^{3+} / \mathrm{N}$ co-doped $\mathrm{TiO}_{2}$ /diatomite granule catalyst with enhanced photocatalytic performance under visible light irradiation. Appl. Surf. Sci. 2018:467-468:514-525. https://doi.org/10.1016/j.apsusc.2018.10.146

[29] Etacheri V., et al. Visible-light activation of $\mathrm{TiO}_{2}$ photocatalysts: Advances in theory and experiments. J. Photochem. Photobiol. C Photochem. Rev. 2015:25:1-29. https://doi.org/10.1016/j.jphotochemrev.2015.08.003

[30] Xiu Z., et al. $\mathrm{Ti}^{3+}-\mathrm{TiO}_{2} / \mathrm{Ce}^{3+}-\mathrm{CeO}_{2}$ Nanosheet heterojunctions as efficient visible-light-driven photocatalysts. Mater. Res. Bull. 2017:100:191-197. https://doi.org/10.1016/j.materresbull.2017.12.016

[31] Xiu Z., et al. Recent advances in $\mathrm{Ti}^{3+}$ self-doped nanostructured $\mathrm{TiO}_{2}$ visible light photocatalysts for environmental and energy applications. Chem. Eng. J. 2019:382:123011. https://doi.org/10.1016/j.cej.2019.123011

[32] Bui V. K. H., et al. Titanium dioxide microscale and macroscale structures: A mini-review. Nanomaterials 2020:10(6):1-31. https://doi.org/10.3390/nano10061190

[33] Reghunath S., et al. A review of hierarchical nanostructures of $\mathrm{TiO}_{2}$ : Advances and applications. Appl. Surf. Sci. Adv. 2021:3:100063. https://doi.org/10.1016/j.apsadv.2021.100063

[34] Yin J. J., et al. Phototoxicity of nano titanium dioxides in HaCaT keratinocytes-Generation of reactive oxygen species and cell damage. Toxicol. Appl. Pharmacol. 2012:263(1):81-88. https://doi.org/10.1016/j.taap.2012.06.001

[35] Shah S. N. A., et al. Hazardous Effects of Titanium Dioxide Nanoparticles in Ecosystem. Bioinorg. Chem. Appl. 2017:4101735. https://doi.org/10.1155/2017/4101735

[36] Wang S. S., et al. Photocatalytic performance of $\mathrm{TiO}_{2}$ thin films deposited on soda-lime glass and the effect of postannealing on their properties. J. Comput. Theor. Nanosci. 2014:11(7):1667-1673. https://doi.org/10.1166/jetn.2014.3549

[37] Yu J., Zhao X. Effect of substrates on the photocatalytic activity of nanometer $\mathrm{TiO}_{2}$ thin films. Mater. Res. Bull. 2000:35(8):1293-1301. https://doi.org/10.1016/S0025-5408(00)00327-5

[38] Magnone E., et al. Facile synthesis of TiO2-supported $\mathrm{Al} 2 \mathrm{O} 3$ ceramic hollow fiber substrates with extremely high photocatalytic activity and reusability. Ceram. Int. 2020:47(6):7764-7775. https://doi.org/10.1016/j.ceramint.2020.11.121

[39] Kim C., et al. Immobilization of $\mathrm{TiO}_{2}$ on an ITO substrate to facilitate the photoelectrochemical degradation of an organic dye pollutant. Electrochim. Acta 2009:54(24):5715-5720. https://doi.org/10.1016/j.electacta.2009.05.018

[40] Medvids A., et al. Anatase or rutile $\mathrm{TiO}_{2}$ nanolayer formation on Ti substrates by laser radiation: Mechanical, photocatalytic and antibacterial properties. Opt. Laser Technol. 2020:138:106898. https://doi.org/10.1016/j.optlastec.2020.106898

[41] Gualdrón-Reyes A. F., et al. Effect of Metal Substrate on Photo(electro)catalytic Activity of B-Doped Graphene Modified $\mathrm{TiO}_{2}$ Thin Films: Role of Iron Oxide Nanoparticles at Grain Boundaries of $\mathrm{TiO}_{2}$. J. Phys. Chem. C 2018:122(1):297-306. https://doi.org/10.1021/acs.jpcc.7b08059

[42] Yang J. H., Han Y. S., Choy J. H. TiO 2 thin-films on polymer substrates and their photocatalytic activity. Thin Solid Films 2006:495(1-2):266-271. https://doi.org/10.1016/j.tsf.2005.08.195

[43] Maleki H., Bertola V. $\mathrm{TiO}_{2}$ Nanofilms on Polymeric Substrates for the Photocatalytic Degradation of Methylene Blue. ACS Appl. Nano Mater. 2019:2(11):7237-7244. https://doi.org/10.1021/acsanm.9b01723 
[44] Nam H.-J., et al. Photocatalytic Activity of Sol- $-\mathrm{Gel} \mathrm{TiO}_{2}$ Thin Films on Various Kinds of Glass Substrates: The Effects of $\mathrm{Na}+$ and Primary Particle Size. J. Phys. Chem. B 2004:108(24):8254-8259. https://doi.org/10.1021/jp037170t

[45] Lopez L., et al. Effect of substrate on surface morphology and photocatalysis of large-scale $\mathrm{TiO}_{2}$ films. Appl. Surf. Sci. 2013:265:162-168. https://doi.org/10.1016/j.apsusc.2012.10.156.

[46] Tuckute S., et al. Tailoring of $\mathrm{TiO}_{2}$ film crystal texture for higher photocatalysis efficiency. Appl. Surf. Sci. 2019:489:576-583. https://doi.org/10.1016/j.apsusc.2019.05.341

[47] Lelis M., et al. Tailoring of $\mathrm{TiO}_{2}$ film microstructure by pulsed-DC and RF magnetron co-sputtering. Surf. Coatings Technol. 2019:377:124906. https://doi.org/10.1016/j.surfcoat.2019.124906

[48] ISO 10678:2010: Fine ceramics (advanced ceramics, advanced technical ceramics) - Determination of photocatalytic activity of surfaces in an aqueous medium by degradation of methylene blue.

[49] Naumkin A. V., et al. NIST X-ray Photoelectron Spectroscopy Database, NIST Standard Reference Database 20, Version 4.1. Gaithersburg: National Institute of Standards and Technology, 2012. http://dx.doi.org/10.18434/T4T88K

[50] Enache-Pommer E., Liu B., Aydil E. S. Electron transport and recombination in dye-sensitized solar cells made from single-crystal rutile $\mathrm{TiO}_{2}$ nanowires. Phys. Chem. Chem. Phys. 2009:11(42):9648-9652. https://doi.org/10.1039/B915345D

[51] Hashimoto K., Irie H., Fujishima A. $\mathrm{TiO}_{2}$ Photocatalysis: A Historical Overview and Future Prospects. Jpn. J. Appl. Phys. 2005:44(12):8269-8285. https://doi.org/10.1143/jjap.44.8269

[52] Varnagiris S., et al. Black carbon-doped $\mathrm{TiO}_{2}$ films: Synthesis, characterization and photocatalysis. J. Photochem. Photobiol. A Chem. 2019:382:111941. https://doi.org/10.1016/j.jphotochem.2019.111941

[53] Domínguez-Espíndola R. B., et al. Photoelectrocatalytic inactivation of fecal coliform bacteria in urban wastewater using nanoparticulated films of $\mathrm{TiO}_{2}$ and $\mathrm{TiO}_{2} / \mathrm{Ag}$. Environ. Technol. 2017:38(5):606-614. https://doi.org/10.1080/09593330.2016.1205148

[54] Wang W., et al. Advances in photocatalytic disinfection of bacteria: Development of photocatalysts and mechanisms. J. Environ. Sci. 2015:34:232-247. https://doi.org/10.1016/j.jes.2015.05.003.

[55] Yu J. C., et al. Photocatalytic Activity, Antibacterial Effect, and Photoinduced Hydrophilicity of $\mathrm{TiO}_{2}$ Films Coated on a Stainless Steel Substrate. Environ. Sci. Technol. 2003:37(10):2296-2301. https://doi.org/10.1021/es0259483

[56] Hu H., et al. Preparations of $\mathrm{TiO}_{2}$ film coated on foam nickel substrate by sol-gel processes and its photocatalytic activity for degradation of acetaldehyde. J. Environ. Sci. 2007:19(1):80-85. https://doi.org/10.1016/S1001$\underline{0742(07) 60013-8}$ 